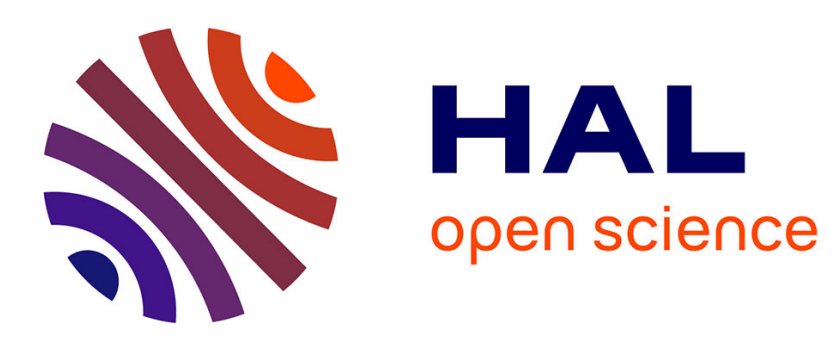

\title{
Hydrogen as a combustion enhancer for highly efficient ultra-lean spark-ignition engines
}

\author{
Jean-Marc Zaccardi, Guillaume Pilla
}

\section{To cite this version:}

Jean-Marc Zaccardi, Guillaume Pilla. Hydrogen as a combustion enhancer for highly efficient ultralean spark-ignition engines. SAE International journal of advances and current practices in mobility, 2019, 10.4271/2019-01-2258 . hal-02294350

\section{HAL Id: hal-02294350 \\ https://hal-ifp.archives-ouvertes.fr/hal-02294350}

Submitted on 23 Sep 2019

HAL is a multi-disciplinary open access archive for the deposit and dissemination of scientific research documents, whether they are published or not. The documents may come from teaching and research institutions in France or abroad, or from public or private research centers.
L'archive ouverte pluridisciplinaire HAL, est destinée au dépôt et à la diffusion de documents scientifiques de niveau recherche, publiés ou non, émanant des établissements d'enseignement et de recherche français ou étrangers, des laboratoires publics ou privés. 


\title{
Hydrogen as a combustion enhancer for highly efficient ultra-lean spark-ignition engines
}

\author{
Author, co-author (Do NOT enter this information) \\ Affiliation (Do NOT enter this information. It will be pulled from participant tab in MyTechZone)
}

Copyright $\odot 2019$ SAE Japan and Copyright $\odot 2019$ SAE International

\begin{abstract}
Performance of lean burn gasoline spark-ignition engines can be enhanced through hydrogen supplementation. Thanks to its physicochemical properties, hydrogen supports the flame propagation and extends the dilution limits with improved combustion stability. These interesting features usually result in decreased emissions and improved efficiencies which is of the utmost importance for future $\mathrm{SI}$ engines targeting ultra-lean conditions at $\lambda \geq 2$ and brake thermal efficiencies above $50 \%$. Compared to previous studies of hydrogen supplementation, this article aims at demonstrating how hydrogen can support the combustion process with a modern combustion system optimized for extreme dilution rates and high efficiency. Experimental investigations performed with a single cylinder engine are reported and show that the minimal amount of hydrogen required to reach $\lambda=2$ is in the range of 2 to $4 \%$ of the total intake volume flow rate. At low load, NOx emissions can be lowered down to $33 \mathrm{ppm}$ at $\lambda=2$ and results also show that a 10 -fold decrease in NOx emissions is possible when the dilution rate increases from the lean limit without hydrogen up to $\lambda=2$. In those ultra-lean conditions, particle emissions are also significantly lowered. Unburned energy is around $5 \%$ in low load conditions at $\lambda=2$ but the engine-out unburned hydrocarbon concentration is maintained at an acceptable level. At high load, combustion timings can be improved thanks to the increase in the maximal dilution rate and to the better auto-ignition resistance of hydrogen. Consequently, the indicated efficiency is increased by more than $6 \%$ abs. compared to the reference stoichiometric conditions. Finally, a maximal indicated efficiency of $47.0 \%$ is obtained at $\lambda=2$ with $3 \%$ of hydrogen at $3000 \mathrm{rpm}-13$ bar IMEP. For this operating point, similar performance are obtained with a dual air/EGR dilution.
\end{abstract}

\section{INTRODUCTION}

From a global point of view, the use of hydrogen is in line with the current trend that aims at increasing the
$\mathrm{H} / \mathrm{C}$ ratio of transportation fuels to reduce $\mathrm{CO}_{2}$ emissions. More specifically, hydrogen can be used in internal combustion engines to improve their efficiency and performance. The main interesting physicochemical properties of hydrogen are compared to those of a standard gasoline fuel in Table 1. As it can be seen in this table, hydrogen has a higher Research Octane Number (RON) than gasoline and thus potentially a higher resistance to knocking combustion, a much higher laminar flame speed, but also a much lower lean extinction limit than gasoline. Those properties contribute to extend the dilution limits and to improve the combustion stability.

Table 1. Main characteristics of $\mathrm{E} 10$ and $\mathrm{H}_{2}$ fuels

\begin{tabular}{|l|c|c|c|}
\hline \multicolumn{2}{|c|}{ Fuels properties } & Gasoline & $\mathrm{H}_{2}$ \\
\hline $\begin{array}{l}\text { Laminar flame speed (standard } \\
\text { conditions, stoichiometric mixture) }\end{array}$ & {$[\mathrm{cm} / \mathrm{s}]$} & $\approx 40$ & $\approx 185$ \\
\hline Research Octane Number & {$[-]$} & $95-98$ & $>120$ \\
\hline Lean limit extinction & {$[-]$} & $0.5-0.6$ & $\approx 0.1$ \\
\hline Minimum Ignition Energy & {$[\mathrm{mJ}]$} & 0.24 & 0.02 \\
\hline $\begin{array}{l}\text { Quenching distance in air (NTP } \\
\text { conditions) }\end{array}$ & {$[\mathrm{mm}]$} & 2.0 & 0.64 \\
\hline Lower Heating Value & {$[\mathrm{MJ} / \mathrm{kg}]$} & $41-42$ & 120 \\
\hline
\end{tabular}

The use of hydrogen as a combustion "booster" has already been reported in the literature for both compression ignition and Spark-Ignition (SI) engines [1-16]. Usually, a few percent of hydrogen in volume is added to the intake air to improve the combustion characteristics in terms of combustion timing and speed, combustion stability, and pollutant emissions. Hydrogen supplementation was considered since the 1970s in order to improve the dilution resistance of lean burn SI engines. Houseman and Hoehn [1] reported in 1974 the results of $\mathrm{H}_{2}$ addition in a V8 engine running in ultra-lean conditions. $\mathrm{H}_{2}$ was produced by a compact hydrogen generator using a partial oxidation process between gasoline and air thus producing a gaseous stream containing $23 \%$ vol. $\mathrm{H}_{2}$ and $24 \%$ vol. CO. Low NOx emissions and an approximate $10 \%$ reduction in brake specific fuel consumption was then measured in lean conditions 
but a bottleneck on unburned hydrocarbon emissions (uHC) and carbon monoxide (CO) was already identified.

Thanks to single cylinder engine and vehicle tests, researchers from General Motors [2-3] confirmed these observations at the same period and reached air-fuel ratios $(\lambda)$ around 1.8 thanks to hydrogen-supplemented fuel (the supplementation process being defined as the use of the minimum hydrogen amount required to reach a given dilution rate, while the enrichment process consists in using more hydrogen as required to reach a given a dilution rate). The control of uHC emissions in lean conditions and the definition of a suitable source of hydrogen on-board were identified as the two major challenges for hydrogen-supplementation.

A few years later, Varde [4] highlighted the positive impact of hydrogen addition on the flame speed in lean conditions thanks to two ionization probes mounted in the cylinder head of an air cooled single cylinder engine.

The impacts of hydrogen-supplementation were studied in both compression ignition and spark-ignition engines with various fuels. Schafer [5] showed that SI engines could be run with hydrogen and methanol in ultra-lean conditions (equivalence ratios down to around 0.4 ) while controlling the $\mathrm{uHC}$ emissions. Yan et al. [6] recently provided a review on the performance of hydrogen enriched compressed natural gas engines. This survey of recent studies focuses mainly on natural gas engines nevertheless several key phenomena regarding the impact of hydrogen are the same for gasoline fueled engines: enhanced initial flame kernel development, faster flame propagation process, reduction of carbon emissions and more complete combustions, and improved combustion performance in lean conditions.

$\mathrm{Ji}$ et al. [7] demonstrated the positive impacts of hydrogen at stoichiometric conditions using a 4-cylinder engine with gasoline and hydrogen port fuel injection systems. Small hydrogen fractions proved to be efficient to reduce unburned hydrocarbon emissions thanks to the short quenching distance of hydrogen and to improve the engine brake thermal efficiency. However, because of stoichiometric conditions and inhomogeneity of the in-cylinder charge, increases in NOx and $\mathrm{CO}$ emissions were also observed. In 2009, Ji et al. [8-9] also reported some results obtained in lean conditions with a $1.6 \mathrm{~L}$ 4-cylinder engine and with 3 to $6 \%$ vol. $\mathrm{H}_{2}$. At idle [8], increase in $\mathrm{uHC}$ emissions could be measured because of partial combustion and low cylinder temperature. Such increase was not observed at $1400 \mathrm{rpm}$ low load [9] even if leaner mixtures could be reached (up to $\lambda=1.65$ ).

Hydrogen direct injection combined with EGR dilution and stoichiometric mixtures was also studied by Du et al. [10]. It was reported that the physical and chemical properties of hydrogen can improve engine tolerance to EGR and reduce $\mathrm{uHC}$ and $\mathrm{CO}$ emissions. Compared to the works of $\mathrm{Ji}$ et al. [7], it was also reported that the NOx emissions can be controlled if hydrogen injection is combined with EGR.

Researchers at MIT also studied how combustion in SI engines could be enhanced with hydrogen by considering an on-board production with a plasmatron [11-12]. In both cases, not only hydrogen was used to enhance the combustion process but a mixture of $\mathrm{H}_{2}, \mathrm{CO}$ and $\mathrm{N}_{2}$. Knock-limited performances in stoichiometric conditions were analyzed by Gerty et al. [11] for three fuel types. The combustion delay due to knock could be reduced thanks to hydrogen addition. Estimations have shown that the higher auto-ignition resistance of hydrogen-supplemented fuel could be combined to an increase in compression ratio of around 3.5 points. In parallel, effects of hydrogen enhancement were studied in lean and EGR-diluted mixtures by Ivanič et al. [12]. Results show that the effect of EGR on NOx emissions is slightly greater than the effect of excess air but with lower engine efficiency.

As shown with this short literature review, the use of hydrogen in internal combustion engines is not new and many references reporting the positive impacts of hydrogen on combustion can be found. In the case of SI engines, these references address stoichiometric combustion, lean burn [13-14] or other approaches requiring high dilution rates. This is the case for example for the D-EGR concept developed by Southwest Research Institute [15], or also for Ohtomo et al. [16] using hydrogen to support the flame propagation process and study the auto-ignition intensity in highly diluted mixtures with air or with EGR.

Overall, hydrogen supplementation in lean conditions has a positive impact on $\mathrm{CO}$ and $\mathrm{CO}_{2}$ emissions and very low NOx emissions can also be measured depending on the dilution level. Clear benefits on the combustion speed and timing can also be obtained which results in improved combustion stability and higher efficiency. However, two main bottlenecks can be identified for hydrogen supplementation. The first one concerns $\mathrm{uHC}$ emissions for which contradictory results can be found in the literature, and the second one concerns the overall energy efficiency taking into account the hydrogen production means.

In the future, ultra-lean mixtures in SI engines will be required to achieve very high efficiency and hydrogen supplementation is a potential solution to support the combustion process in those ultra-lean conditions targeting $\lambda \geq 2$, and maximal brake thermal efficiencies higher than $50 \%$. The objective of this article is to propose an update of the information already available in the literature thanks to new test results obtained with a modern engine optimized for a high dilution resistance and high efficiency. In this study, the impacts of $\mathrm{H}_{2}$ in ultra-lean conditions have been investigated experimentally with a single cylinder engine. The next sections will introduce first the experimental setup, and then the results of investigations performed in low, mid and high load conditions. 


\section{ENGINE CONFIGURATION}

The test campaign was performed with a direct injection single cylinder engine using a compression ratio of $14: 1$ and an Early Intake Valve Closing (EIVC) timing strategy (intake valve lift of $1 \mathrm{~mm} 30 \mathrm{CAD}$ before bottom dead center). The intake ports of this engine were specifically developed and optimized to achieve a very high charge motion, enabling thus the use of EIVC strategy and the extension of the dilution limits with air and EGR. Table 2 summarizes the main characteristics of this engine.

Table 2. Single cylinder engine main characteristics.

\begin{tabular}{|l|l|l|}
\hline Cylinder displacement & {$\left[\mathrm{cm}^{3}\right]$} & 410.9 \\
\hline Valves & {$[-]$} & 4 \\
\hline Stroke & {$[\mathrm{mm}]$} & 93.0 \\
\hline Bore & {$[\mathrm{mm}]$} & 75.0 \\
\hline Compression ratio & {$[-]$} & $14: 1$ \\
\hline Tumble motion & {$[-]$} & 2.4 \\
\hline Intake valve lift duration & {$[C A D]$} & 140 \\
\hline EVC / IVO @ 1 mm lift & {$[C A D$ aTDC] } & $-10 / 10$ \\
\hline E10 injection mode & {$[-]$} & Direct injection \\
\hline $\mathrm{H}_{2}$ injection mode & {$[-]$} & Port Injection \\
\hline
\end{tabular}

For these tests, hydrogen was added at the intake in counter-flow with the air motion using a gas diffuser. The hydrogen flow rate was adjusted with a Bronkhorst mass flow controller. In the following paragraphs, the amount of $\mathrm{H}_{2}$ added at the intake will be given as a fraction of the intake volume flow rate (air and hydrogen). Equivalent mass and energy fractions are given in Table 3. Since a negative valve overlap was used for the tests, hydrogen was not directly scavenged towards the exhaust but remained in the combustion chamber.

Table 3. $\mathrm{H}_{2}$ concentrations.

\begin{tabular}{|l|c|c|c|}
\cline { 2 - 4 } \multicolumn{1}{c|}{} & $\begin{array}{c}2000 \mathrm{rpm} \\
4 \text { bar IMEP }\end{array}$ & $\begin{array}{c}2000 \mathrm{rpm} \\
18 \text { bar IMEP }\end{array}$ & $\begin{array}{c}3000 \mathrm{rpm} \\
13 \text { bar IMEP }\end{array}$ \\
\hline$\lambda$ & $2 \rightarrow 1$ & $1.62 \rightarrow 1$ & $2 \rightarrow 1$ \\
\hline $\mathrm{H}_{2}$ vol. $\%$ & $\approx 3$ & $\approx 4$ & $\approx 3$ \\
\hline $\mathrm{H}_{2}$ mass $\%$ & $\approx 3.1-6.5$ & $\approx 4.3-7.2$ & $\approx 3.1-6.2$ \\
\hline $\mathrm{H}_{2}$ energy $\%$ & $\approx 8.4-16.8$ & $\approx 11.5-18.3$ & $\approx 8.6-16.2$ \\
\hline
\end{tabular}

As for the fuel a commercial E10 gasoline was used. Gasoline was directly injected (central position) with a constant injection pressure of 200 bar. The gasoline fuel consumption was measured with a Coriolis flowmeter. Gasoline injection and ignition timings were controlled with an in-house control module. Oil, coolant and fuel were supplied by electrically driven pumps. Oil and coolant temperatures were maintained at $90^{\circ} \mathrm{C} \pm 2^{\circ} \mathrm{C}$ and tests were performed only in steady-state conditions. The pressurized intake air was provided by an external compressor through a sonic flow meter and a flap was used in the exhaust line to simulate the backpressure of a turbine. Intake, exhaust, and in-cylinder pressures were measured with conventional sensors (water-cooled at the exhaust and inside the cylinder) and the measurements were post-processed with an in-house software to calculate the combustion characteristics (heat release rate and mass fraction burned). The concentration of the main pollutants $(\mathrm{uHC}, \mathrm{CO}$ and NOx) were measured with conventional gas analyzers. The smoke emissions were measured with an AVL 415S smoke meter and particle emissions (mass and number) were measured with a Pegasor Particle Sensor. The exhaust line was completed with a lambda sensor.

Investigations were performed for several operating points and for each of them the dilution rate by air, $E G R$, or both, has been varied in order to quantify the impacts of hydrogen on the combustion stability limits with diluted mixtures. It was considered that the maximal dilution rate was reached when the coefficient of variation of Indicated Mean Effective Pressure (IMEP) exceeded 3\% (usual and relevant threshold to characterize the combustion stability except at very low load conditions such as idle).

Spark-timing was adjusted for all the different cases in order to achieve the optimal 50\% MFB angle at low engine load ( 6 to 7 CAD aTDC) or the knock-limited $50 \%$ MFB angle at high engine load.

This paper focuses on three operating points: 2000 rpm - 4 bar IMEP (low load), 3000 rpm - 13 bar (mid-load) and $2000 \mathrm{rpm}$ - 18 bar (high load). The analysis highlights the impact of hydrogen on combustion stability and pollutant emissions, on knocking resistance and on maximal efficiency. Other operating points were investigated, and the results of their analysis is presented in Appendix 2.

\section{LOW LOAD INVESTIGATIONS AT 2000 RPM}

As a first step, the combustion stability was quantified as a function of the dilution rate and of the hydrogen amount. Figure 1 illustrates the results obtained at 2000 rpm - 4 bar IMEP. Figure 1 a) shows first that the minimal amount of hydrogen required to reach $\lambda=2$ with a stable combustion process is between 2 and $3 \%$ for this operating point. Figure $1 \mathrm{~b}$ ) also shows that the maximal dilution rate is around $\lambda=1.63$ without hydrogen.
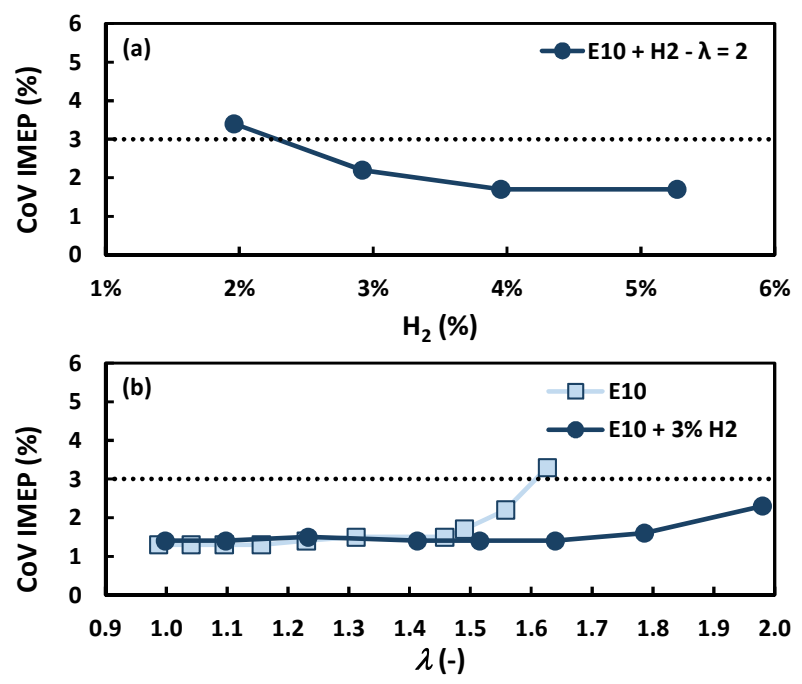

Figure 1. CoV of IMEP at $\lambda=2$ (a) and as a function of the dilution rate (b) for a 2000 rpm - 4 bar IMEP operating point. 
The NOx formation process is mainly related to the Zeldovich mechanism correlating the temperature increase and the NOx concentration [17]. For this reason, the NOx emissions are increased with $\mathrm{H}_{2}$ addition because of the higher combustion speed leading to a higher combustion temperature as shown in Figure 2 a). However, thanks to hydrogen, the combustion process can be supported and remains very stable even in ultra-lean conditions. The lean mixtures can then lead to very low NOx emissions, down to $33 \mathrm{ppm}(0.23 \mathrm{~g} / \mathrm{kW} . \mathrm{h})$. A 7 -fold decrease in NOx emissions can be observed between the lean limit without $\mathrm{H}_{2}(\lambda=1.63)$, and the lean limit with $\mathrm{H}_{2}$ $(\lambda=1.98)$. Adomeit et al. [18] have reported similar trends and NOx emissions below 50 ppm for $\lambda$ values higher than 1.85 for this same operating point.

As expected, Figure $2 \mathrm{~b}$ ) shows that the dilution rate is the most influencing factor concerning $\mathrm{CO}$ emissions. However, a positive effect of hydrogen can be observed since $\mathrm{CO}$ emissions can be reduced by around $0.9 \mathrm{~g} / \mathrm{kW}$.h from $\lambda=1.1$ up to $\lambda=1.63$ compared to the $\lambda$ variation performed without $\mathrm{H}_{2}$. A slight increase is of $0.2 \mathrm{~g} / \mathrm{kW}$.h then observed at $\lambda=1.98$ when the combustion stability limit is reached.

Figure 2 c) clearly shows the positive impact of hydrogen addition on indicated unburned hydrocarbon emissions. These emissions are reduced by $1.7 \mathrm{~g} / \mathrm{kW} . \mathrm{h}$ at $\lambda=1$, and by $5.5 \mathrm{~g} / \mathrm{kW}$.h at $\lambda=1.63$ (lean limit without $\mathrm{H}_{2}$ ). Several effects can explain this improvement. It can be assumed first that the mixture homogeneity is improved with hydrogen supplemented fuel because less liquid gasoline fuel is injected in the combustion chamber, and because of the high diffusion speed of hydrogen in the intake air. It can thus be assumed that the intake air / $\mathrm{H}_{2}$ mixture is perfectly homogeneous and that the resulting overall reactivity of the fresh air / $\mathrm{H}_{2} / \mathrm{E} 10$ mixture inside the combustion chamber is more homogeneous, and that the mixture can be more fully burned. Hydrogen also benefits from a shorter quenching distance than gasoline, which means that the flame can propagate closer to the walls and burn more mixture before being extinguished. However, in both cases (with and without hydrogen), uHC emissions increase with the dilution rate because the temperature levels inside the combustion chamber and ports are decreasing. Close to the combustion stability limits $(\lambda=1.63$ and $\lambda=1.98$ without and with hydrogen respectively), increases in uHC emissions are observed not only because of the decreasing temperature in the combustion chamber but also because of the downgraded combustion stability which leads to incomplete burning of the mixture (it can be noted that no misfire are to be reported for these results). This increase is particularly sharp without hydrogen between $\lambda=1.56$ and $\lambda=1.63$, thus following the stability increase shown in Figure $1 \mathrm{~b}$ ). Thanks to the lower quenching distance of hydrogen, the increase in $\mathrm{uHC}$ emissions is smoother even at higher $\lambda$ values. Even close to the stability limit at $\lambda=1.98$, uHC emissions are still lower than at $\lambda=1.63$ without hydrogen. This is a key aspect of ultra-lean burn combustion, it is not only necessary to reach high dilution rates but also to achieve a complete combustion to control the uHC emissions. The engine used for these tests is particularly well adapted to these investigations because it was developed to implement a very strong tumble motion to support the combustion process with high dilution rates (air or EGR), and for EIVC timing strategies. This is an important development observed in recent years compared to engines used in previous studies with hydrogen-supplemented fuels.

Figure $2 \mathrm{c}$ ) also points out that the $\mathrm{uHC}$ concentration at the exhaust at $\lambda=1.98$ is in the order of $3400 \mathrm{ppmC}$, which corresponds to the same order of magnitude as the concentrations recently taken as reference by Takeori et al. [19-20] at $1500 \mathrm{rpm}$ - 4 bar IMEP for the development of an optimized after-treatment system for lean-burn SI engines complying with SULEV regulations. Further improvements are however required to further reduce the $\mathrm{uHC}$ emissions which is the major cause of efficiency downgrading at high dilution rates.
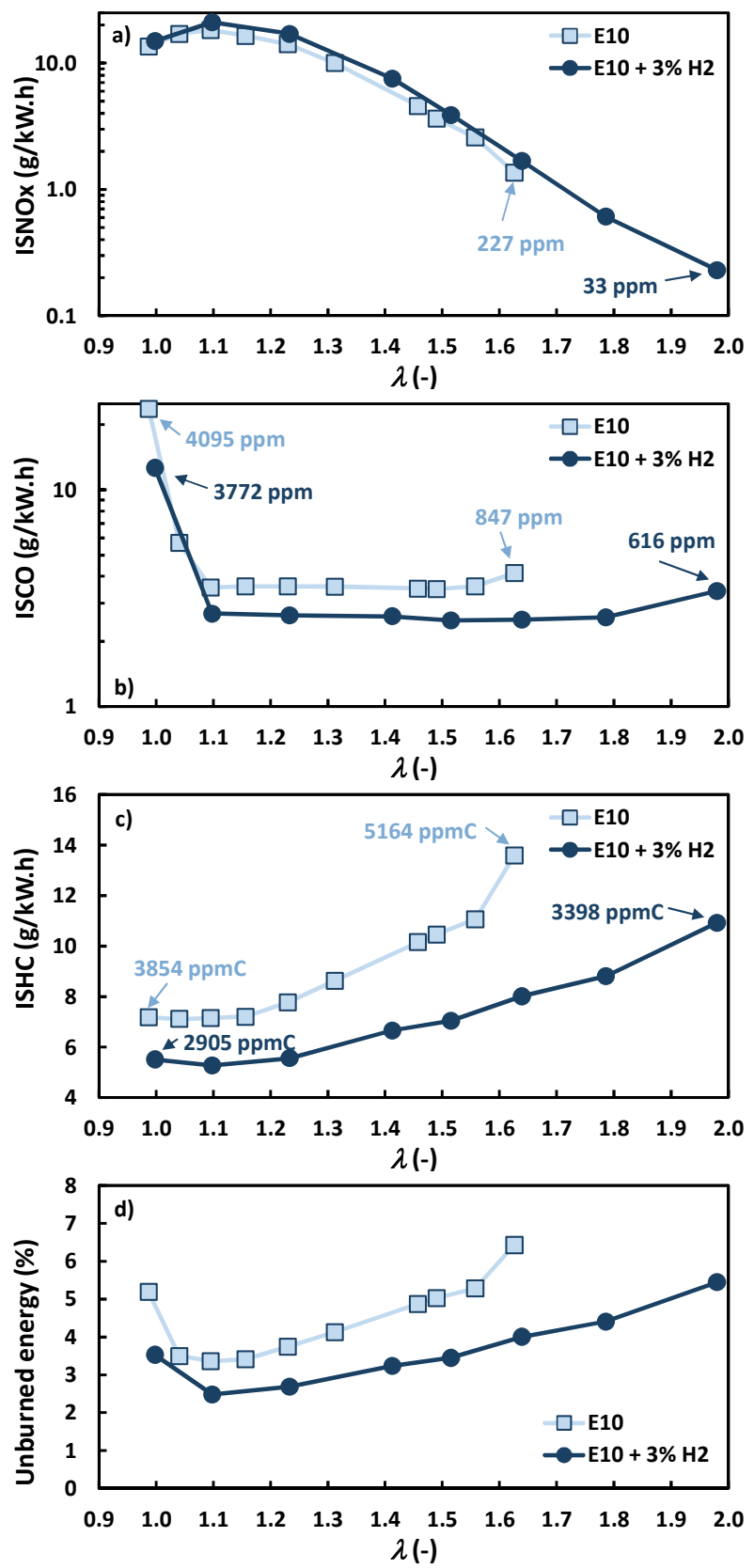

Figure 2. Indicated pollutant emissions and unburned energy as a function of the dilution rate for a $2000 \mathrm{rpm}$ - 4 bar IMEP operating point. 
Figure $2 \mathrm{~d}$ ) shows the relative unburned energy ( $\mathrm{uHC}$ and $\mathrm{CO}$ ) as a function of the dilution rate. The trend observed close to stoichiometric conditions is mostly related to $\mathrm{CO}$ emissions while the trend observed in lean conditions is mostly related to $\mathrm{uHC}$ emissions. In ultra-lean conditions, the relative unburned energy is kept around $5 \%$ for this operating point, lower than for the lean limit without hydrogen. As mentioned above, some additional measures are required to further reduce the $\mathrm{uHC}$ emissions in order to improve the efficiency.

A decrease in smoke emissions was also observed when the air dilution rate was increased without and with hydrogen. However, these emissions were already extremely low for stoichiometric conditions (below 0.03 fsn at $\lambda=1$ ). Particle mass and number emissions also decreased from around $2000.10^{3} / \mathrm{cm}^{3}$ and $0.43 \mathrm{mg} / \mathrm{m}^{3}$ at $\lambda=1$ down to $175.10^{3} / \mathrm{cm}^{3}$ and $0.036 \mathrm{mg} / \mathrm{m}^{3}$ at $\lambda=1.98$ (see Figure 3 ). For this operating point, a 12-fold decrease in particle emissions was thus measured when comparing the results at $\lambda=1$ and close to $\lambda=2$, and this reduction was even more important for the other investigated operating points since the base emissions were higher (see Appendix 2). Smoke and particles emissions are lowered with $\mathrm{H}_{2}$ thanks to a faster combustion process, to the lower quenching distance of hydrogen resulting in a more complete fuel oxidation, to the overall reduced liquid fuel share inside the combustion chamber, and also thanks to the more interesting $\mathrm{H} / \mathrm{C}$ fuel ratio (which also has a significant impact on the reduction of $\mathrm{HC}$ and $\mathrm{CO}$ emissions).
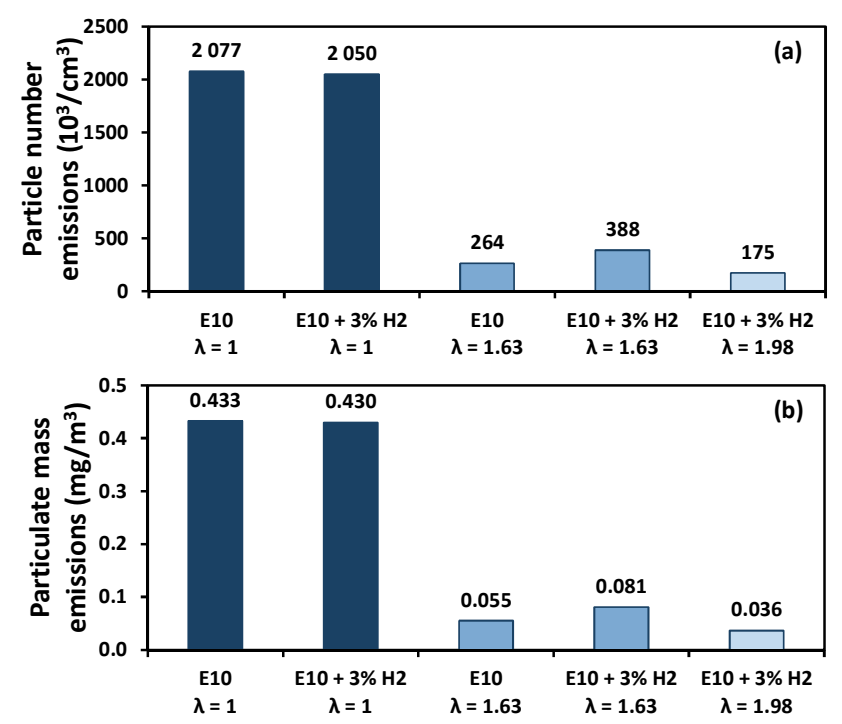

Figure 3. Particle number (a) and mass (b) emissions as a function of the dilution rate for a $2000 \mathrm{rpm}$ - 4 bar IMEP operating point.

The positive impact of hydrogen on the maximal Heat Release Rate (HRR) is shown in Figure 4. The same maximal HRR is reached at $\lambda=2$ with hydrogen, as that at $\lambda=1.63$ without hydrogen, namely around $0.04 \mathrm{CAD}^{-1}$. It is usually observed that unstable combustions occur when the mean value of the maximal HRR is lower than $0.04 C A D^{-1}$ depending on the engine configuration, not only for lean mixtures, but also when EGR dilution is used. It is shown for example by de Francqueville and Michel with EGR at high load [21], and it can also be derived from the results reported in lean conditions by Hanabusa et al. [22].

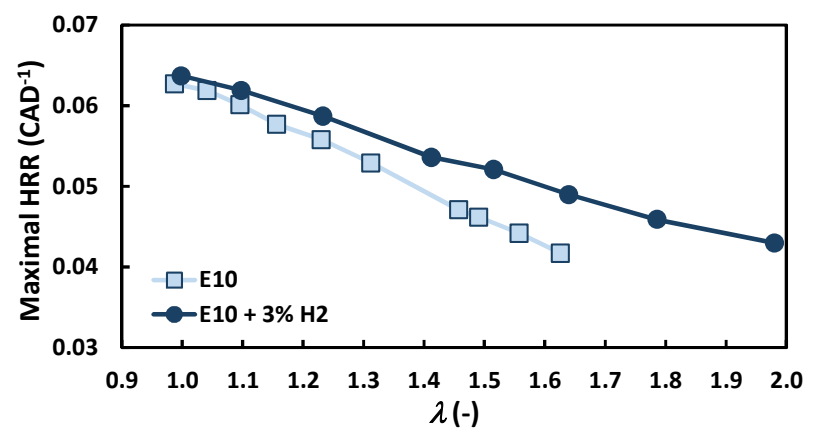

Figure 4. Maximal heat release rate as a function of the dilution rate for a 2000 rpm - 4 bar IMEP operating point.

Figure 5 compares the heat release rates obtained at $\lambda=1.63$ without and with hydrogen, and at $\lambda=2$ with hydrogen. This comparison shows that very similar heat release rates can be obtained with ultra-lean mixtures when the combustion process is enhanced by hydrogen. The three cases shown in Figure 5 have similar combustion timings of 6,7 and 8 CAD aTDC and it can be reasonably assumed that this limited variation has no impact on efficiency since the efficiency variation is very flat close to the optimal combustion timing.

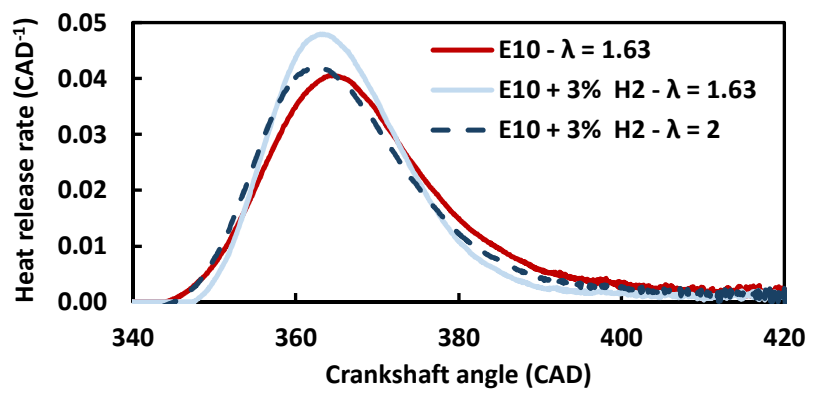

Figure 5. Heat release rates comparison for a 2000 rpm - 4 bar IMEP operating point.

For this operating point, the maximal indicated efficiency can be increased by $2 \%$ abs. from $38.3 \%$ up to $40.3 \%$ thanks to the leaner mixtures that can be achieved with hydrogen (see Figure 6 ). Up to $\lambda=1.5$, similar efficiencies are obtained without or with hydrogen since in both cases the combustion speed are relatively high and the combustion timings are always optimal (knock free operation for this low load). Pumping losses are also very similar and the unburned energy is also quite similar in both cases (see Figure 2). However, the maximal indicated efficiency is obtained at around $\lambda=1.8$ and not at $\lambda=1.98$ because of the increase in unburned energy. It means that a better trade-off between efficiency and $\mathrm{uHC}$ emissions could be obtained without reaching the dilution limit with hydrogen which would remain beneficial for NOx emissions reduction. Adomeit et al. [18] have reported a similar maximal efficiency of around $38 \%$ at $\lambda=1.6$ but here higher efficiencies are reached thanks to the additional dilution up to $\lambda=1.8$. It can also be noted that this indicated efficiency is related to the total fuel injected in the combustion chamber (including thus gasoline and hydrogen) but that the energy required to produce hydrogen is not taken into account. 


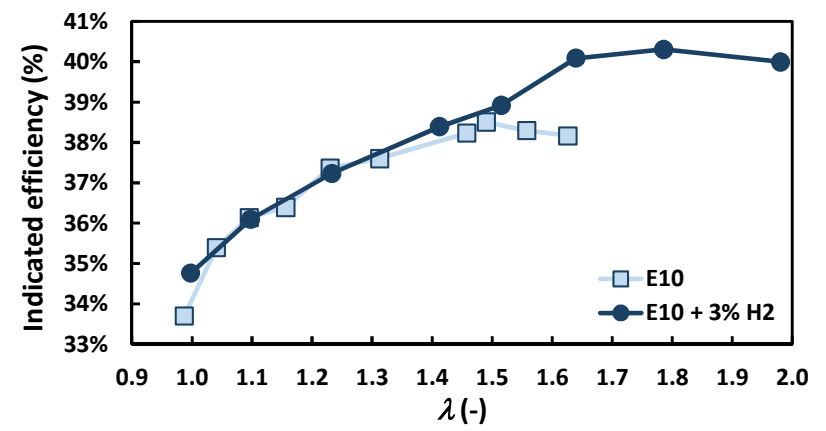

Figure 6. Impacts of hydrogen on indicated efficiency as a function of the dilution rate for a 2000 rpm - 4 bar IMEP operating point.

\section{HIGH LOAD INVESTIGATIONS AT 2000 RPM}

Investigations performed at $2000 \mathrm{rpm}, 18$ bar IMEP are reported here. The main benefit of hydrogen at high load lies in its strong auto-ignition resistance. A small amount of hydrogen can then be used to improve the knocking resistance and to reach earlier combustion timings, i.e. better combustion phasings.

Theoretically, it is possible to improve the combustion timing and to reach $\lambda=2$ at high load with a stable combustion process. However, $\lambda=2$ could not be reached at $2000 \mathrm{rpm}, 18$ bar IMEP because the maximal allowed peak firing pressure of 120 bar for this engine was almost reached (see Appendix 1). In these conditions, no additional dilution was considered because it was feared that earlier spark-timings could lead to critical knock events. Lean mixtures require high boosting pressures, and despite the EIVC timing strategy, the effective compression ratio remains quite high starting from a geometric compression ratio of 14:1. Consequently, the resulting peak firing pressure was the limiting factor for this operating point, and not the combustion stability. A maximal dilution rate of $\lambda=1.62$ was reached with $4 \%$ vol. of $\mathrm{H}_{2}$, and in these conditions the CoV of IMEP was $2.7 \%$ while the limit peak firing pressure of 120 bar was reached.

Figure 7 shows that the combustion timing can be improved thanks to lean mixtures with hydrogen. This figure also shows that the combustion timing is downgraded between $\lambda=1$ and $\lambda=1.2$ with or without hydrogen. This downgrading is due to the increase in boost pressure and it is necessary to further increase the dilution rate to observe a positive impact of dilution on auto-ignition resistance. The knock-limited $50 \%$ MFB angle can then be significantly improved by several crank angle degrees. Without hydrogen, the combustion timing was so delayed at $\lambda=1.2$ (close to 35 CAD aTDC) that unstable combustion events were observed and no further dilution could be accepted. Thanks to these better combustion timings, the maximal HRR can be maintained above the $0.04 \mathrm{CAD}^{-1}$ mentioned earlier, even for high dilution rates (see Figure 7).

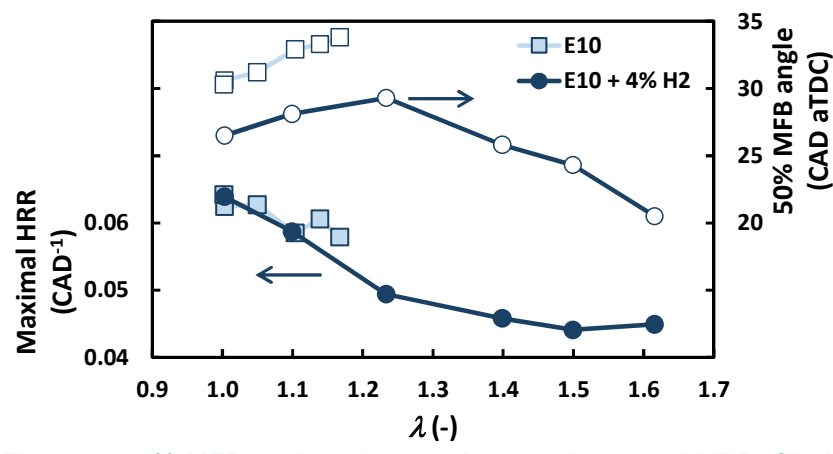

Figure 7. 50\% MFB angle (white symbols) and maximal HRR (filled symbols) as a function of the dilution rate for a 2000 rpm - 18 bar IMEP operating point.

Dilution enhanced by hydrogen, combined with improved combustion timings and proper combustion speeds lead to a significant increase in indicated efficiency as shown in Figure 8. Starting from stoichiometric conditions, an increase by more than $6 \%$ abs. was observed and this efficiency could still be further increased if the engine had been designed for peak firing pressures above 120 bar. Between $\lambda=1$ and $\lambda=1.2$, a better efficiency is obtained with hydrogen thanks to the improved combustion timings only. All the other relevant parameters are very similar with or without hydrogen as it was shown in Figure 7 for the combustion speed, and as it is shown in Figure 9 for unburned energy and pumping losses.

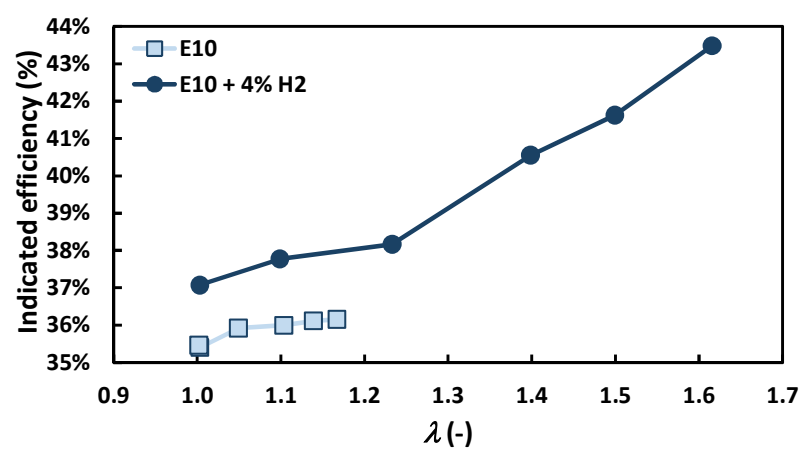

Figure 8. Impacts of hydrogen on indicated efficiency as a function of the dilution rate for a 2000 rpm - 18 bar IMEP operating point.

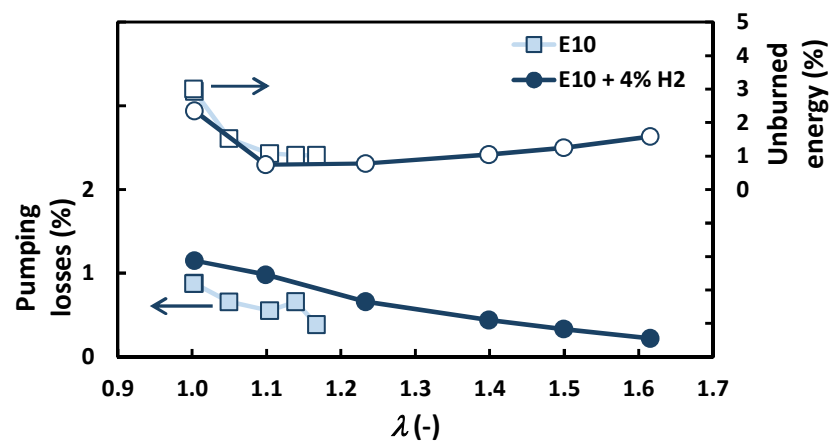

Figure 9. Unburned energy (white symbols) and pumping losses (filled symbols) as a function of the dilution rate for a $2000 \mathrm{rpm}$ 18 bar IMEP operating point.

It must be noted that pumping losses depend here on the turbocharging model used for the single cylinder engine tests. This is an essential parameter for quantifying the engine performance at full load. A representative in-house model of a single stage turbocharger featuring a variable geometry turbine was used for these tests to define the exhaust backpressure to be applied for each operating point (see Figure 10). This type of turbocharger is still under 
development for $\mathrm{SI}$ engines but should soon be applied in series. This model has the particularity of being relatively favorable on this operating point at low engine speed since the combustion chamber scavenging could be possible (not used here because of the negative valves overlap). Based upon Figure 10, it can also be assumed that boost pressures above 3.0 bar abs. will be required to reach $\lambda=2$ at full load.

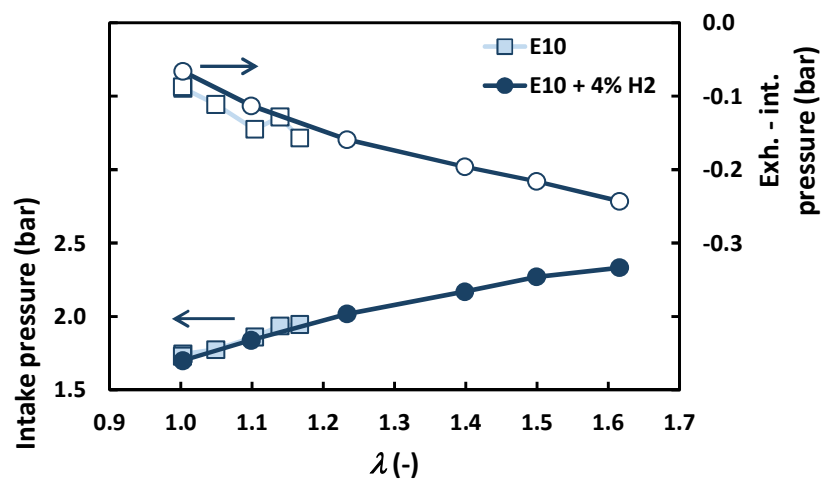

Figure 10. Intake pressure (filled symbols) and pressure differential (white symbols) as a function of the dilution rate for a $2000 \mathrm{rpm}$ 18 bar IMEP operating point.

\section{MID LOAD INVESTIGATIONS AT 3000 RPM}

Previous experimental and numerical analyses have shown that the maximal efficiency can usually be expected at mid load in the range of 2500-3000 rpm where the overall trade-off between pumping losses and knocking resistance is improved. Moreover, accordingly with available results in the literature [23], results obtained at $2000 \mathrm{rpm}-18$ bar IMEP showed that air dilution might not be the most effective solution to improve the knocking resistance. This is one of the reasons why the dual air/EGR dilution is the investigated path in the Japanese SIP consortium for ultra-diluted highly efficient SI engines [24].

Consequently, a dual dilution with air and EGR was also tested at $3000 \mathrm{rpm}-13$ bar IMEP and three $\lambda$ variations were then performed:

- without hydrogen, and without EGR;

- with a constant amount of hydrogen (3\% vol.) but without EGR;

- with increasing amounts of EGR in lean conditions. In this last case, the minimal amount of hydrogen required to reach stable combustions was used for each tested EGR rate.

In lean conditions, EGR includes not only burned gases (such as $\mathrm{CO}_{2}$ and $\mathrm{H}_{2} \mathrm{O}$ ), but also oxygen and nitrogen that is why the following results in Figure 11 have been plotted as a function of the in-cylinder air-fuel ratio. The EGR rate variation has been performed in order to reach the same maximal overall dilution rate as with air only, $\lambda=1.91$ and $\lambda=1.97$ respectively.

Figure 11 shows that optimal $50 \%$ MFB angles can be reached when EGR is combined with air at extreme dilution rates (at $\lambda=1.84$ and $\lambda=1.91$ ). The operating point at $\lambda=1.84$ is incidentally the only case for which the indicated efficiency is slightly better with EGR and air combined: $47.2 \%$ against $47 \%$ with air only at $\lambda=1.97$. However, when the maximal EGR rate is reached, the combustion speed is decreased and despite the better combustion timing the efficiency is not further increased.

All the differences in terms of efficiency are mostly related here to combustion timing and in a lesser extent to combustion speed since very similar pumping losses and unburned energies are obtained with air dilution, and with the dual dilution approach (see Appendix 3).

It can also be noted in Appendix 3 that NOx emissions close to $\lambda=2$ are very similar for both dilution types, around $0.85 \mathrm{~g} / \mathrm{kW} . \mathrm{h}$ (around $180 \mathrm{ppm}$ ).
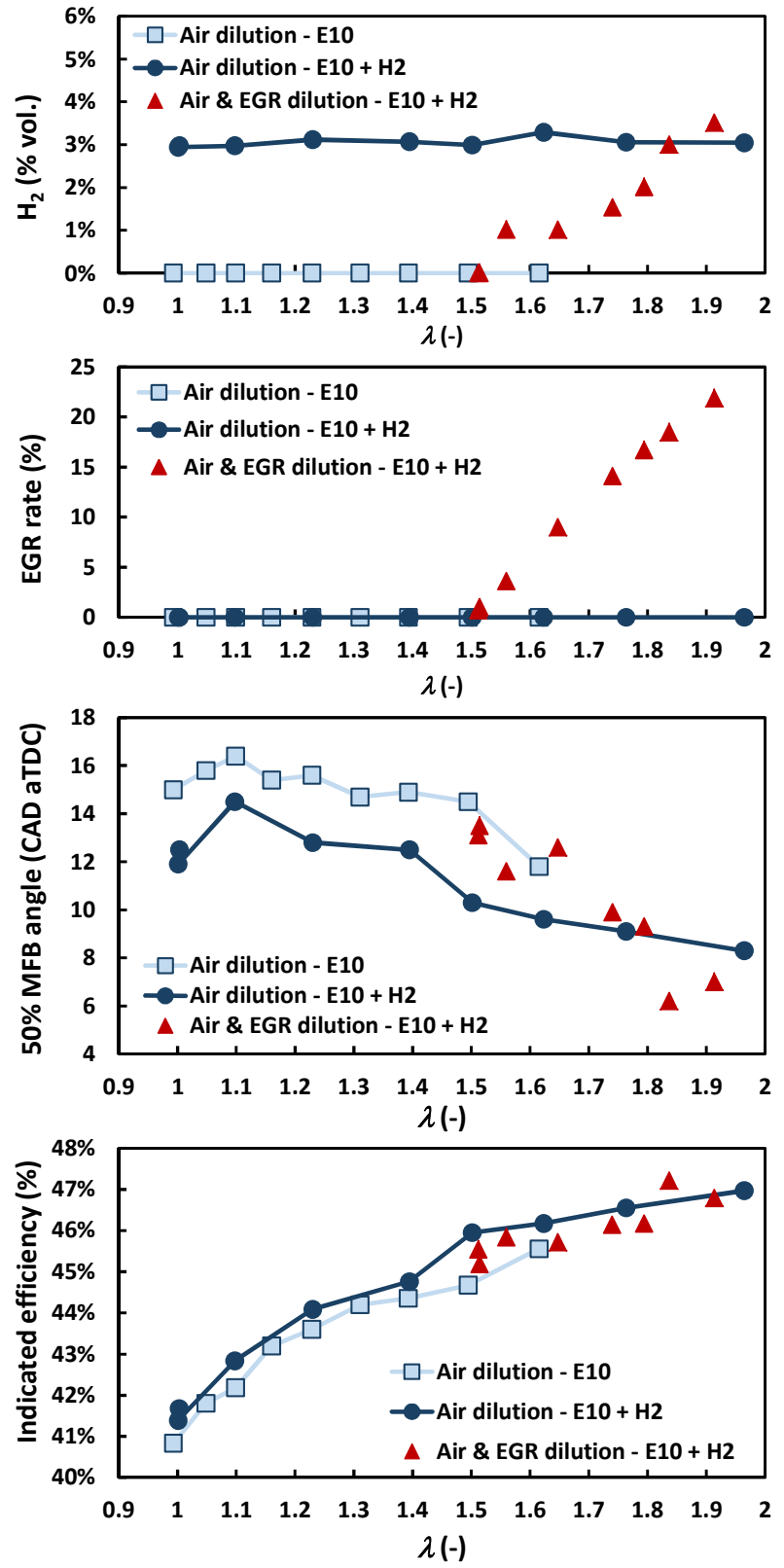

Figure 11. Impacts of air dilution, and air \& EGR dilution on combustion timing and indicated efficiency for a 3000 rpm - 13 bar IMEP operating point.

A split-of-losses analysis [25] has been performed for the operating point achieving the maximal indicated efficiency with air dilution. Figure 12 shows the results of this analysis starting from the reference cycle with an indicated efficiency of $47.3 \%$, up to the theoretical cycle (Beau de Rochas cycle) with an indicated efficiency of around $65.1 \%$. The reference cycle is 
simulated based upon the experimental boundary conditions, which explains that the indicated efficiency is slightly higher than that obtained during the tests. The heat balance obtained for this reference cycle is shown in Table 4. The unburned energy is quite significant, around $3.5 \%$, which means that the indicated efficiency could be first increased if the fuel oxidation process could be enhanced (leading to lower $\mathrm{UHC}$ and $\mathrm{CO}$ emissions). Cooling losses stand here for around $12 \%$ of the fuel energy but it must be noted that these are only the cooling losses inside the combustion chamber. The cooling losses due to heat exchanges in the exhaust ports are included in the exhaust losses.

Table 4. Heat balance for the reference cycle at $\lambda=1.97$ with air dilution only

\begin{tabular}{|l|c|}
\hline Indicated efficiency & $47.3 \%$ \\
\hline Unburned energy & $3.5 \%$ \\
\hline Exhaust losses & $37.2 \%$ \\
\hline Cooling losses & $12.0 \%$ \\
\hline Total & $100.0 \%$ \\
\hline
\end{tabular}

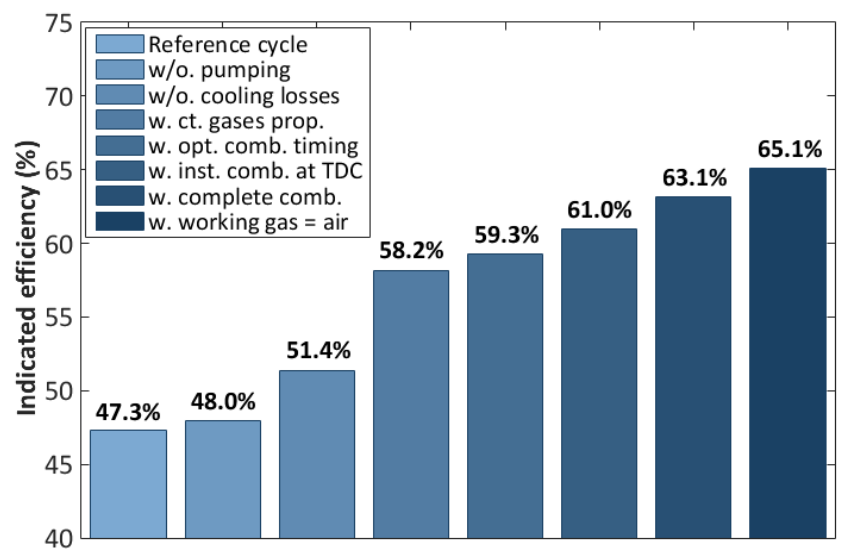

Figure 12. Split-of-losses analysis at $\lambda=1.97$ with air dilution only.

The results of the split-of-losses analysis are as follows.

- Figure 12 shows first that the indicated efficiency would not be significantly improved by decreasing pumping losses which account for about $0.7 \%$ abs. As mentioned above this is attributed to the turbocharging model used at the test bed for the single cylinder engine.

- The indicated efficiency is decreased by around $3.4 \%$ abs. due to the cooling losses inside the combustion chamber (from $51.4 \%$ down to $48.0 \%$ ). Cooling losses cannot be fully cancelled but can still be further decreased to improve the efficiency.

- The temperature impact on the mixture's heat capacity and polytropic coefficient stands for a significant part of the losses. This aspect could be improved for example by further diluting the mixture to limit this impact of temperature on the fluids thermodynamic properties (which would remain, however, lower than the polytropic coefficient of cold air as for the theoretical cycle).

- The efficiency could then be increased by around $1.1 \%$ abs. (from $58.2 \%$ up to $59.3 \%$ ) if an optimal combustion timing could be reached. This increase is rather limited because the combustion timing obtained with $3 \%$ of $\mathrm{H}_{2}$ at $\lambda=2$ is almost optimal (see Figure 11).

- The potential increase in efficiency related to the combustion speed is around $1.7 \%$ abs. (from $59.3 \%$ up to $61.0 \%$ ). Indeed, the maximal combustion speed is rather low even with $\mathrm{H}_{2}$ and could be improved.

- Accordingly with the heat balance shown in Table 4 , the unburned energy stands for a significant part of the energy losses and the efficiency could be increased by $2.1 \%$ abs. (from $61.0 \%$ up to $63.1 \%)$ if $\mathrm{uHC}$ and $\mathrm{CO}$ emissions could be fully cancelled.

- Finally, the split-of-losses analysis quantifies the impact of the air dilution rate on efficiency compared to the theoretical cycle for which only air is considered as working fluid. For this last step, the efficiency could be increased by $2 \%$ abs. if the air/fuel mixture at $\lambda=2$ could be replaced by air only.

This split-of-losses analysis makes it possible to identify the potential solutions that deserve to be investigated in order to reach indicated efficiencies greater than $50 \%$. The first aspect to be optimized concerns the reduction of $\mathrm{uHC}$ emissions in order to minimize the unburned energy since a more complete combustion would directly result in an increased efficiency. Then, a further increase in air dilution should make it possible to increase the efficiency by a decrease of the cooling losses (step 2 in Figure 12), by a decrease of the gas temperature (related to step 3 in Figure 12), and thanks to mixture properties that would be closer to those of pure air (last step in Figure 12).

Nevertheless, an overall efficient trade-off will have to be found since even more diluted mixtures will certainly call into question the weight of the pumping losses because higher boosting pressures would be required, but with lower exhaust temperatures. Higher dilution rates will also have consequences on the combustion velocity, and thus on its stability and on $\mathrm{uHC}$ emissions. It is therefore essential to find a technological approach to ensure a fast and complete combustion.

\section{DISCUSSION}

\section{EXHAUST TEMPERATURE}

Extending the dilution limit up to $\lambda=2$ and above will have some significant consequences on the turbocharging and after-treatment systems because of the decrease in exhaust enthalpy. Very low exhaust temperatures between 350 and $400^{\circ} \mathrm{C}$ have been measured at the outlet of exhaust ports at $\lambda=2$ for engine speeds lower than $3000 \mathrm{rpm}$ and IMEP lower than 10 bar. In any case, the exhaust temperature decreases almost linearly as long as $\lambda$ increases as shown in Figure 13. 


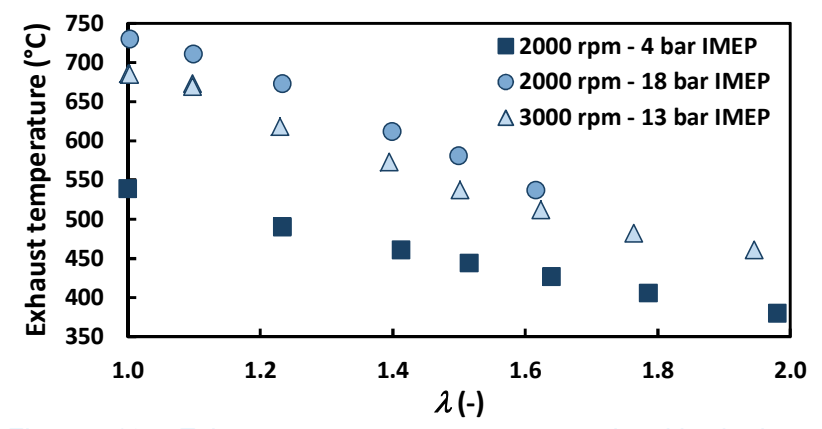

Figure 13. Exhaust temperatures measured with hydrogen enhanced combustion in ultra-lean conditions (at the exhaust ports outlet).

This temperature decrease is critical for the development of the turbocharging system. Indeed, efficient turbochargers will be required for future lean burn SI engines to provide the necessary boosting pressure with a good efficiency to prevent from downgrading the improved combustion efficiency obtained thanks to ultra-lean mixtures. Different solutions can be considered such as variable turbines, double stage turbocharging systems, or single stage electrically assisted turbochargers and the final choice will not only depend on energy efficiency, but also on transient performance [18].

The low exhaust temperatures at the turbine outlet will also be a challenging aspect for the optimization of after-treatment systems. Several layouts are possible for ultra-lean burn applications as shown by Koehler et al. [26]. All the different potential strategies and layouts will aim at taking into account all the possible running modes for the engine (lean or stoichiometric), and all the different running phases from cold start and warm-up to high temperature running conditions at high engine speed and load. Unburned hydrocarbons being emitted mostly during cold start, stoichiometric mixtures combined with a three-way catalyst will certainly be required during warm-up. Then, some specificities related to the nature of uHC emissions in warm lean burn conditions might also have to be considered as shown by Takeori et al. [20]. Regarding NOx emissions, Koehler et al. [26] has shown that the lean-to-stoichiometric time ratio giving the optimal $\mathrm{NOx} / \mathrm{CO}_{2}$ trade-off is an essential factor to determine the real fuel consumption benefit that can be achieved in ultra-lean conditions while respecting the emissions limits.

The highly transient operations of lean burn SI engines that will be used in Hybrid Electric Vehicles (HEV) and Plug-in HEV (PHEV) will be another challenge both for after-treatment systems that will have to be maintained in warm conditions, but also for the turbocharging system that will have to ensure strong and sudden torque demands. It will surely be difficult to realize these transient phases in lean conditions.

\section{ENGINE DESIGN}

The main objective of this experimental campaign was to quantify the amount of hydrogen required to increase the air dilution rate $\lambda$ up to 2 over the whole engine map and the engine characteristics were selected in order to maximize its efficiency, especially thanks to a high compression ratio of $14: 1$. However, combining such a high compression ratio and ultra-lean mixtures at high load leads to very high cylinder pressure, particularly when the combustion timing can be improved thanks to hydrogen addition. It is therefore necessary to design the engine components for much higher peak firing pressures than those usually considered for SI engines in order to take advantage of the full benefit of hydrogen addition over the whole engine map. With this ultra-lean approach, it can be assumed that intake pressure could be higher than 3.5 bar abs. and maximal peak firing pressure could reach 180 bar depending on the considered intake valve lifts and on compression ratios. Compared to usual SI engines, the cylinder head fire deck thickness would have to be increased which will have some strong impacts on the cylinder head cooling circuit and consequently on the cylinder head walls temperature and on the injector cooling in case of direction injection engines. From a general perspective, the different possible approaches for achieving efficiencies above $50 \%$ will all require to design new engines for increased peak firing pressure above 150 bar.

\section{HYDROGEN PRODUCTION}

This article primarily focuses on the effects of hydrogen on combustion and its main objective is to highlight the opportunities offered by hydrogen to enhance the combustion process in lean conditions. The aspects related to hydrogen production are thus dissociated from the aspects related to combustion. The energy required for hydrogen production has deliberately not been taken into account above because these works did not intend to carry out a detailed well-to-wheel analysis. As an energy carrier, hydrogen could be used in many different ways: as a direct and single fuel for internal combustion engines or for fuel cells, as a supplemental fuel for internal combustion engines, or as an intermediate product to store green electricity or even to produce e-fuels. In the case of automotive applications and regarding the works reported here, different production means could be considered and hydrogen could be stored in an externally refillable tank, or directly produced on-board (with or without any storage). In any case, the overall energy balance will depend on the selected hydrogen production chain. For some of them, the engine fuel consumption reduction achieved thanks to ultra-lean mixtures can be completely counterbalanced by the energy costs of hydrogen production.

\section{CONCLUSION}

Experimental investigations were performed with a single cylinder engine in order to quantify the impacts of hydrogen supplementation in ultra-lean conditions for several operating points. Detailed results for three operating points are reported in this article to highlight the impacts of hydrogen on combustion stability, pollutant emissions, knocking resistance and efficiency. The main conclusions of these experimental investigations are as follows: 
1. The minimal amount of $\mathrm{H}_{2}$ required to reach $\lambda=2$ is in the range of 2 to $4 \%$ of the total intake volume flow rate for all the investigated operating points.

2. At $\lambda=2$, NOx emissions can be lowered down to $0.23 \mathrm{~g} / \mathrm{kW}$.h (33 ppm) at $2000 \mathrm{rpm}$ - 4 bar IMEP and below $0.5 \mathrm{~g} / \mathrm{kW}$.h for IMEP lower than 6 bar.

3. For the same operating point, heat release rates obtained at $\lambda=2$ with $\mathrm{H}_{2}$ are very similar to those obtained without $\mathrm{H}_{2}$ at $\lambda=1.6$.

4. At $\lambda=2$, smoke and particles emissions can be significantly lowered when $\mathrm{H}_{2}$ is added at the intake thanks to an overall improved combustion process.

5. Unburned energy can reach up to $5 \%$ in low load conditions at $\lambda=2$ but $\mathrm{uHC}$ concentration at the exhaust can be maintained at an acceptable level.

6. At high load, combustion timings can be improved by several crank angle degrees thanks to $\mathrm{H}_{2}$ addition.

7. At $3000 \mathrm{rpm}$ - 13 bar IMEP, a maximal indicated efficiency of $47.0 \%$ can be reached at $\lambda=2$ with $3 \%$ of $\mathrm{H}_{2}$ (compared to $45.6 \%$ at $\lambda=1.61$ without $\mathrm{H}_{2}$ for the same operating point). For the same operating point, similar results are obtained with air dilution and with the dual air and EGR dilution.

8. Exhaust temperatures as low as $350^{\circ} \mathrm{C}$ can be reached at the exhaust ports outlet in low load conditions at $\lambda=2$.

Those experiments were performed with a classical ignition system using a spark-plug. Further investigations are on-going using an optimized combustion system and a scavenged pre-chamber ignition system [27-28]. The combined effects of $\mathrm{H}_{2}$ and a pre-chamber ignition system will be quantified over the whole engine map and compared to those obtained with a conventional spark-plug ignition system. It will also be possible to evaluate the amount of $\mathrm{H}_{2}$ required to reach $\lambda=2$ when $\mathrm{H}_{2}$ is injected only in the pre-chamber.

Another perspective following these works would be to further increase the air dilution rate. According to the results presented above, it might not be interesting to increase $\lambda$ above 2 since the efficiency is not continuously increasing and since it will make the development of exhaust after-treatment and turbocharging systems even more challenging. However, it might be a promising solution to reach zero-NOx emissions on a limited operating range which would be particularly suitable for a PHEV application. In this context, a more detailed analysis of particle emissions will also be required.

\section{ACKNOWLEDGMENTS}

This project has received funding from the European Union's Horizon 2020 research and innovation programme under grant agreement No 724084.

The authors would like to thank M. Matrat, T. Colliou and $\mathrm{N}$. Leblanc for their support and for the engine tests.

\section{REFERENCES}

1. Houseman, J. and Hoehn, F., "A Two-Charge Engine Concept: Hydrogen Enrichment," SAE Technical Paper 741169, 1974, https://doi.org/10.4271/741169.

2. Stebar, R. and Parks, F., "Emission Control with Lean Operation Using Hydrogen-Supplemented Fuel," SAE Technical Paper 740187, 1974, https://doi.org/10.4271/740187.

3. Parks, F., "A Single-Cylinder Engine Study of Hydrogen-Rich Fuels," SAE Technical Paper 760099, 1976, https://doi.org/10.4271/760099.

4. Varde, K., "Combustion Characteristics of Small Spark Ignition Engines Using Hydrogen Supplemented Fuel Mixtures," SAE Technical Paper 810921, 1981, https://doi.org/10.4271/810921.

5. Schafer, F., "An Investigation of the Addition of Hydrogen to Methanol on the Operation of an Unthrottled Otto Engine," SAE Technical Paper 810776, 1981, https://doi.org/10.4271/810776.

6. Yan, F., Xu, L., Wang, Y., "Application of hydrogen enriched natural gas in spark ignition IC engines: from fundamental fuel properties to engine performances and emissions," Renewable and Sustainable Energy Reviews, Vol. 82, pp. 1457-1488, 2018, http://dx.doi.org/10.1016/j.rser.2017.05.227.

7. Ji, C., Wang, S., and Yan, H., "Experimental Study on Combustion and Emissions Characteristics of a Spark Ignition Engine Blended with Hydrogen," SAE Technical Paper 2009-01-1923, 2009, https://doi.org/10.4271/2009-01-1923.

8. Ji, C., Wang, S., Effect of hydrogen addition on idle performance of a spark-ignited gasoline engine at lean conditions with a fixed spark advance, Energy Fuels, Volume 23, pp. 4385-4394, 2009, https://doi.org/10.1021/ef900517t

9. Ji, C., Wang, S., Effect of hydrogen addition on combustion and emissions performance of a spark ignition gasoline engine at lean conditions, International Journal of Hydrogen Energy, Volume 34 , Issue 18 , pp. 7823-7834, 2009, https://doi.org/10.1016/j.ijhydene.2009.06.082.

10. Du, Y., Yu, X., Liu, L., Li, R., Zuo, X., Sun, Y., "Effect of addition of hydrogen and exhaust gas recirculation on characteristics of hydrogen gasoline engine," International Journal of Hydrogen Energy, Vol. 42, pp. 8288-8298, 2017, https://doi.org/10.1016/j.ijhydene.2017.02.197.

11. Gerty, M. and Heywood, J., "An Investigation of Gasoline Engine Knock Limited Performance and the Effects of Hydrogen Enhancement," SAE Technical Paper 2006-01-0228, 2006, https://doi.org/10.4271/2006-01-0228.

12. Ivanič, Z., Ayala, F., Goldwitz, J., Heywood, J. B., "Effects of Hydrogen Enhancement on Efficiency and NOx Emissions of Lean and EGR-Diluted Mixtures in a SI Engine," SAE Technical Paper 2005-01-0253, 2005, https://doi.org/10.4271/2005-01-0253. 
13. Jing-ding, L., Ying-ging, L., and Tian-shen, D., "An Experimental Study on Combustion of Gasoline-hydrogen Mixed Fuel," SAE Technical Paper 830897, 1983.

14. Kim, J., Chun, K., Song, S., Baek, H. et al., "Effect of Hydrogen as an Additive on Lean Limit and Emissions of a Turbo Gasoline Direct Injection Engine," SAE Technical Paper 2015-01-1886, 2015, https://doi.org/10.4271/2015-01-1886.

15. Alger, T. and Mangold, B., "Dedicated EGR: A New Concept in High Efficiency Engines," SAE Int. J. Engines 2(1):620-631, 2009, https://doi.org/10.4271/2009-01-0694.

16. Ohtomo, M., Suzuoki, T., Yamamoto, S., and Miyagawa, H., "Effect of Fuel-Air Mixture Dilution on Knock Intensity in an SI Engine," SAE Technical Paper 2018-01-0211, 2018, https://doi.org/10.4271/2018-01-0211.

17. Bowman, C. T., Kinetics of Pollutant Formation and Destruction in Combustion, Prog. Energy Combust. Sci., Vol. 1, Issue 1, 1975, pp. 33-45, https://doi.org/10.1016/0360-1285(75)90005-2.

18. Adomeit, P., Scharf, J., Thewes, M., Morcinkowski, B., Hoppe, P., Esposito, S., Böhmer, M., Extreme Lean Gasoline Technology - Best Efficiency and Lowest Emission Powertrains, $4^{\text {th }}$ International Engine Congress, 2017.

19. Takeori, H., Hosoe, H., Morita, T., and Endo, T., "A Study of Aftertreatment System for Spark-Assisted HCCI Engine," SAE Technical Paper 2015-01-2013, 2015, https://doi.org/10.4271/2015-01-2013.

20. Takeori, H., Wada, K., Matsuo, Y., Morita, T. et al., "Study of an Aftertreatment System for HLSI Lean-burn Engine," SAE Technical Paper 2018-01-0945, 2018, https://doi.org/10.4271/2018-01-0945.

21. Francqueville, L. and Michel, J., "On the Effects of EGR on Spark-Ignited Gasoline Combustion at High Load," SAE Int. J. Engines 7(4):2014, https://doi.org/10.4271/2014-01-2628.

22. Hanabusa, H., Kondo, T., Hashimoto, K., Sono, H. et al., "Study on Homogeneous Lean Charge Spark Ignition Combustion," SAE Technical Paper 2013-01-2562, 2013, https://doi.org/10.4271/2013-01-2562

23. Bourhis, G. and Gautrot, X., "Technological Levers for the Enhancement of Mixture Dilution for Spark Ignited Engines," SIA Powertrain Conference, 2013.

24. lida, N., Research and Development of Super-Lean Burn for High Efficiency SI Engine, The $9^{\text {th }}$ International Conference on Modeling and Diagnostics for Advanced Engine Systems Symposium (COMODIA), 2017.

25. Lecompte, M., Malbec, L., Font, G., and Walter, B., "How to Improve Light Duty Diesel Based on Heavy Duty Diesel Thermodynamic Analysis?," SAE Technical Paper 2013-01-1623, 2013, https://doi.org/10.4271/2013-01-1623.

26. Koehler, E., Osborne, R., Keenan, M., Downes, T., Engine and aftertreatment strategies for lean gasoline engines to meet real driving emissions legislation, SIA Powertrain Conference, 2017.
27. lafrate, N., Zaccardi, J-M., A Numerical Study on Charge Motion Effects in Ultra-Lean Conditions, CONVERGE User conference, 2018.

28. Müller, C., Habermann, K., Morcinkowski, B., Uhlmann, T., Schernus, C., Development of a Pre-chamber for Automobile SI Engine Applications, International Conference on Ignition Systems for Gasoline Engines, 2018.

\section{CONTACT}

Jean-Marc Zaccardi

EAGLE Project Coordinator

Efficient Additivated Gasoline Lean Engine

https://www.h2020-eagle.eu/

j-marc.zaccardi@ifpen.fr

Phone: +33437702063

\section{DEFINITIONS, ACRONYMS, ABBREVIATIONS}

CAD: Crankshaft Angle Degree

CoV: Coefficient of Variation

EGR: Exhaust Gas Recirculation

EIVC: Early Intake Valve Closing

EVC: Exhaust Valve Closing

HEV: Hybrid Electric Vehicle

HRR: Heat Release Rate

IMEP: Indicated Mean Effective Pressure

IVO: Intake Valve Opening

MFB: Mass Fraction Burned

NTP: Normal Temperature and Pressure

PHEV: Plug-in Hybrid Electric Vehicle

RON: Research Octane Number

SI: Spark Ignition

TDC: Top Dead Centre

aTDC: After Top Dead Centre

$\lambda$ : Air-fuel ratio

\section{APPENDIX}

\section{APPENDIX 1}

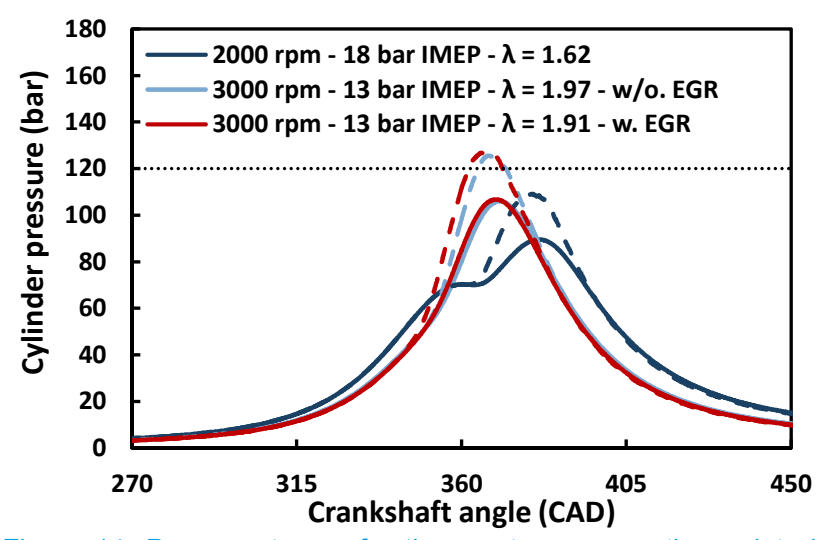

Figure 14. Pressure traces for three extreme operating points in ultra-lean conditions (solid lines: mean cycles, dashed lines: individual cycles with the highest peak firing pressures). 

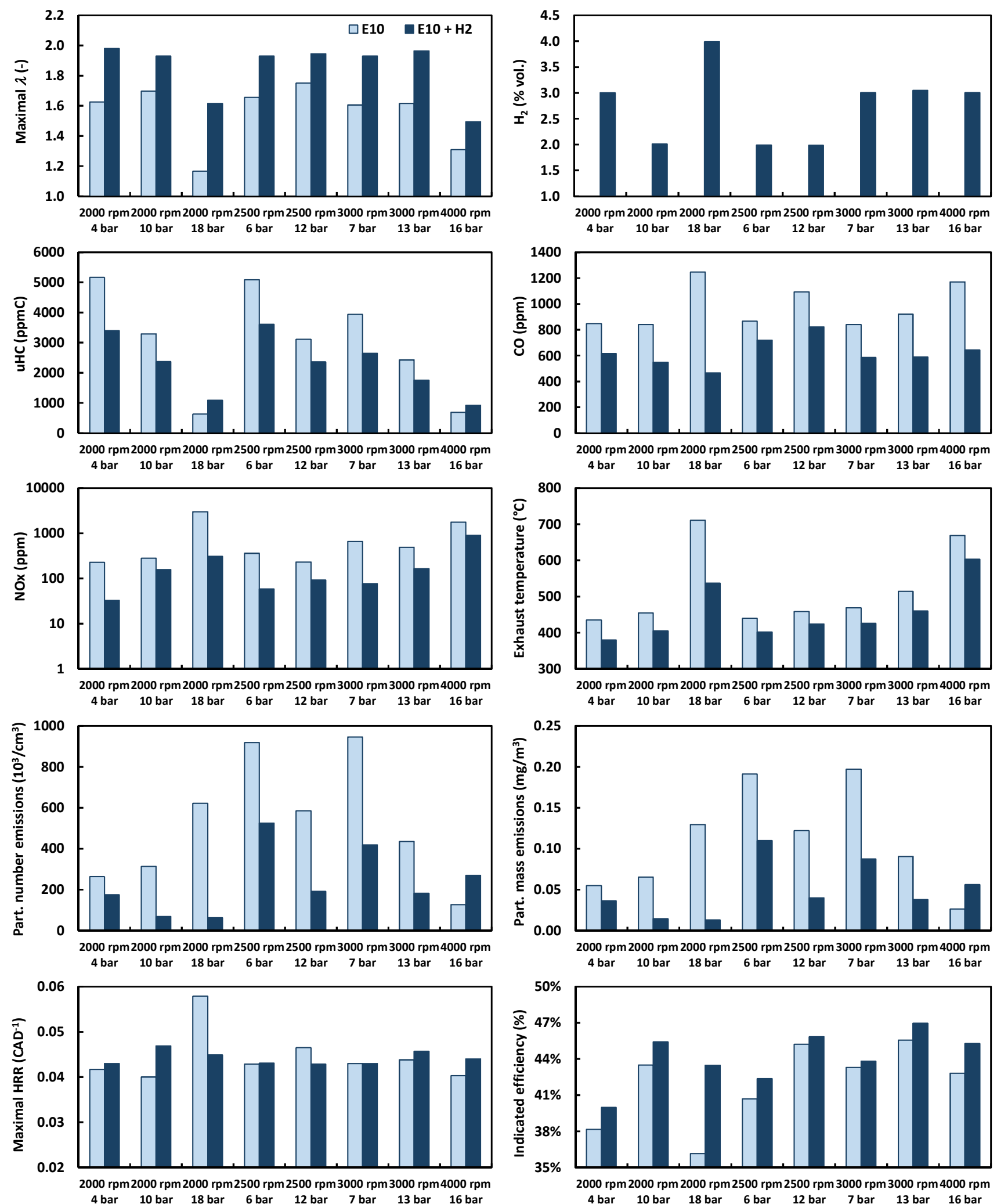

Figure 15. Results overview on eight operating points from 2000 up to $4000 \mathrm{rpm}$, and from 4 to 18 bar IMEP. 

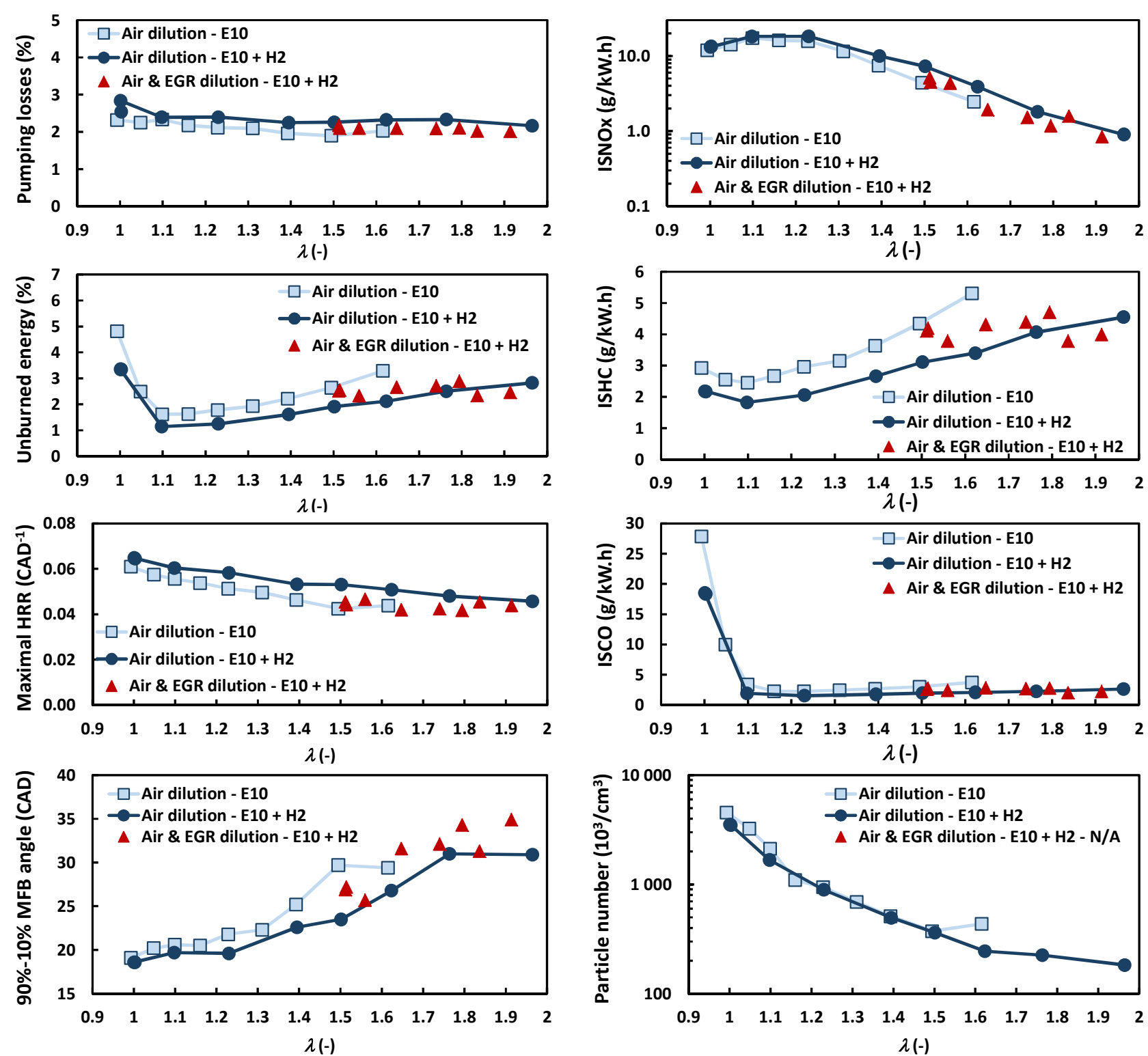

Figure 16. Impacts of air dilution, and air \& EGR dilution at 3000 rpm - 13 bar IMEP (additional results). 